\title{
Implementasi Ontology Pada Web Crawler
}

\section{JASMAN PARDEDE, UUNG UNGKAWA, MUHAMMAD AKBAR BERNOVALDY}

\author{
Jurusan Teknik Informatika, Fakultas Teknologi Industri \\ Institut Teknologi Nasional \\ E-mail : Jasmanpardede78@gmail.com
}

\begin{abstract}
ABSTRAK
Web crawler adalah suatu program atau script otomatis yang bekerja dengan memprioritaskan ketentuan khusus untuk melakukan penjelajahan dan melakukan pengambilan informasi dalam halaman web yang ada di internet. Proses pengindeksan merupakan proses crawler yang memudahkan setiap orang dalam pencarian informasi Pada proses indexing tersebut dibangun dengan menggunakan metode ontology. Metode ontology merupakan sebuah teori tentang makna dari suatu objek dengan hubungan objek tersebut. Pada penelitian ini, metode ontology diterapkan dalam proses pengambilan data dan pengelompokkan data. Metode ontology memiliki proses, yaitu melakukan splitting terhadap objek dengan ketentuan relasi untuk mendapatkan sebuah objek ontology. Selanjutnya dilakukan crawling terhadap objek ontology tersebut untuk mendapatkan hasil crawling dengan ontology. Pengelompokkan data diproses berdasarkan objek yang telah didapat berdasarkan relasi ontology. Dari hasil penelitian dapat diambil kesimpulan, yaitu presentase objek relasi sesuai dengan relasinya adalah $100 \%$ dan kecepatan web crawler dengan ontology lebih cepat $56,67 \%$ dibanding dengan web crawler biasa.
\end{abstract}

Kata kunci : web crawler, ontology, web archiving.

\section{ABSTRACT}

Web crawler is a program or automated script which works by prioritizing specific provisions to browsing and retrieval of information in a web page on the internet. Ontology process are divided by three, is scraping, parsing and indexing. Process of indexing is crawling process that makes it easy everyone search of information. In the process of indexing is built using methods of ontology. Methods of ontology is a theory about the meaning of an object with the object relationship. In this study, the method ontology applied in the data collection process and grouping data. Ontology method has a process of conducting splitting of the object with the provisions of relations to get an object ontology. Furthermore, the crawling towards the ontology objects to get the result crawling with ontology. Grouping the data is processed by an object that has been obtained based on ontology relationships. From the research results can be concluded, that the percentage of object relations in accordance with the relation is $100 \%$ and the speed of a web crawler with ontology $56.67 \%$ faster than regular web crawler.

Keyword : web crawler, ontology, web archiving 


\section{PENDAHULUAN}

Web crawler merupakan suatu program atau script otomatis yang relatif simple karena bekerja dengan metode tertentu untuk melakukan scan atau "crawl" ke semua halaman web di internet untuk membuat indeks dari data yang dicari[6]. Web crawler memiliki tiga proses, yaitu pembacaan halaman (scraping), pemisahan kata (parsing) dan pengindeksan (indexing). Proses pengindeksan (indexing) merupakan proses crawler yang memudahkan setiap orang dalam pencarian informasi. Metode yang dapat digunakan untuk proses pengindeksan adalah metode ontology. Metode ontology merupakan sebuah metode tentang keterkaitan suatu objek dengan objek yang lain berdasarkan sebuah relasi tertentu.

Pada penerapan metode ontology, crawler hanya mengambil halaman yang harus diambil berdasarkan pengelompokkan kategori. Sehingga didapatkan sebuah batasan seperti pengambilan alamat web untuk crawler hanya dari web kompas dan detik, pengindeksan dilakukan pada page 1 dari domain dan sub-domain, data yang digunakan untuk kebutuhan adalah data pada Bulan Oktober 2016, file disimpan dalam bentuk .docx, pengambilan alamat web berdasarkan element yang sudah ditentukan dan studi kasus yang diambil merupakan pengarsipan dari sekali proses crawling.

Pada penelitian ini dibahas bagaimana data diindeks dengan metode ontology, kemudian dilakukan pencocokkan objek ontology dengan relasi ontology dan pengujian respond time pada web crawler. Sehingga didapat hasil implementasi ontology pada web crawler dengan parameter kecocokkan objek ontology dan respond time dari web crawler dengan ontology

\section{METODOLOGI PENELITIAN}

Web crawler menjelajahi halaman web berdasarkan alamat web yang telah diberikan, yaitu kompas.com atau detik.com. Hasil akhir dari web crawler sendiri diaplikasikan sebagai sistem pengarsipan berupa alamat web, judul web dan konten dari web tersebut. Web crawler memiliki tiga proses kerja, yaitu pembacaan halaman (scraping), pemisahan kata (parsing) dan pengindeksan (indexing).

Scraping merupakan proses awal dalam web crawler yang fungsinya untuk mengambil halaman web. Scraping berkaitan erat dengan pengindeksan, seperti untuk bagaimana mengembangkan teknik scrape yaitu dengan terlebih dahulu mempelajari dokumen HTML dari website yang dijelajahi dengan informasi yang diambil berupa tag HTML, tujuannya adalah informasi yang dikumpulkan setelah pembuat program belajar teknik navigasi akan diterapkan ke dalam aplikasi. ${ }^{[1]}$ Dalam langkah pertamanya, scraping bekerja dengan mendapatkan htm/ berdasarkan alamat web yang di-input oleh user. Dokumen $\mathrm{htm} /$ tersebut diuraikan dalam beberapa bagian dengan penandaan kata diantara tanda " $<$ " dan " $>$ ". Tahap terakhir, pembacaan kata tersebut dibagi dalam tag html, body dan head, dimana sekumpulan kode dibaca dan dibagi dalam ketiga bagian tersebut.

Web crawler memisahkan kata dari keseluruhan halaman berdasarkan link yang diambil. Tiap link dalam halaman didefinisikan dengan sebuah penanda untuk pembacaan sebuah link, yaitu element "a href". Pemisahan kata sendiri dalam web crawler digunakan untuk pengambilan link atau pranala link tertentu.

Proses pengambilan data pada kata yang telah dipisah berdasarkan element "a href": $<$ a href= "http://megapolitan.kompas.com" $>$ 
$<$ a href= "http://nasional.kompas.com">

Hasil proses parsing ini adalah sebuah link (alamat web) yang ada pada dokumen html yang telah di-scraping

http://megapolitan.kompas.com

http://nasional.kompas.com

Indexing merupakan sebuah proses dimana metode ontology diterapkan. Pada penelitian ini, proses pengelompokkan ontology dilakukan berdasarkan pengelompokkan kategori. Kategori merupakan sebuah kelompok yang terdiri dari alamat web tertentu yang memiliki relasi sebagai bagian dari alamat web utama. Ontology sendiri diterapkan pada proses indexing karena proses indexing merupakan sebuah proses yang berfungsi untuk memudahkan penyimpanan informasi dalam proses pencarian di search engine. Pada proses indexing juga memudahkan penerapan metode ontologykarena dalam proses ini pengelompokkan dilakukan dengan membedakan setiap bagian. Sehingga penerapan ontology yang membedakan sebuah makna berdasarkan ketentuan relasi dapat diterapkan.

Indexing dilakukan dengan splitting sebuah kata berdasarkan pemisahan tanda "/". Tahap kedua, pengecekkan kata yang telah dipisah dengan ketentuan relasi ontology. Setiap kata dari alamat web yang dipisah berdasarkan tanda "/" dicocokkan dengan kode kategori dan kode alamat web dari ketentuan relasi ontology. Kata-kata yang telah sesuai dikelompokkan berdasarkan objek ontology yang didapat dari ketentuan relasi. Sekumpulan kata tersebut yang berupa alamat web yang terindeks dengan pengelompokkan kategori adalah indexing ontology.

Ontology merupakan suatu teori atau metode tentang makna dari suatu objek, properti dari suatu objek, serta relasi objek tersebut yang mungkin terjadi pada suatu domain pengetahuan. Ontology dapat diartikan juga sebagai penjelasan sebuah konsep yang memiliki hubungan atau kaitan dari ilmu tertentu. Sebuah ontology terdiri dari sebuah daftar istilah terbatas dan hubungan diantara istilah-istilah ${ }^{[3]}$. Ontology biasanya disusun sebagai serangkaian konsep yang memiliki keterkaitan semantic. Semantik adalah cabang linguistik yang mempelajari secara khusus tentang arti, perubahan arti, dan prinsip hubungan antaran kata dan artinya. Sebuah ontology adalah spesifikasi yang eksplisit dan formal dari sebuah konseptualisasi.[7]

Adapun struktur ontology sederhana ditampilkan pada Gambar 1. Pada Gambar 1, Main Object merupakan sebuah istilah untuk objek yang menjadi sebuah pusat dari hubungan ontology atau istilah-istilah yang saling memiliki relasi. Relasi adalah sebuah keterkaitan atau hubungan yang menghubungkan dua objek atau lebih. Sedangkan object adalah istilah-istilah yang berelasi dari objek utama tersebut. 


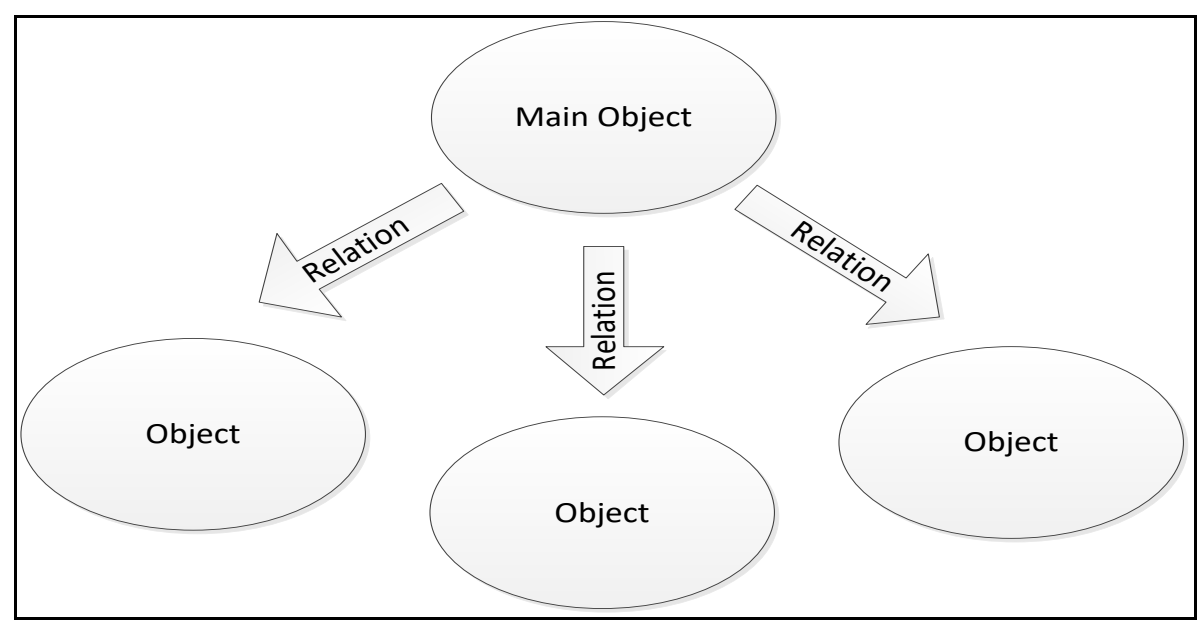

Gambar 1. Struktur Ontology

Proses penerapan ontology dalam indexing memerlukan beberapa kebutuhan data. Analisis kebutuhan data untuk metode ontology diproses menjadi sebuah kata kunci khusus dalam membantu pemrosesan web crawler dengan ontology. Kebutuhan data diambil berdasarkan pengumpulan data sampel yang diperoleh dari website kompas dan detik pada bulan Oktober 2016, dengan didapatkan kesimpulan, yaitu :

1. Data relasi ontology ditampilkan pada Tabel 1 merupakan sebuah kata kunci yang bekerja sebagai relasi dalam hubungan ontology. Kata kunci atau relasi tersebut didapat berdasarkan sebuah keterkaitan yang dimiliki objek utama. Keterkaitan yang dijadikan acuan pada penelitian ini adalah sebuah relasi berdasarkan "kategori" yang dimiliki oleh website yang menjadi objek utama.

2. Data kode judul, berupa inisialisasi kode yang digunakan untuk penentuan judul yang diambil dari kata atau bagian terakhir pada alamat web yang setiap kata atau bagiannya dipisah oleh "/".

3. Data element konten artikel yang ditampilkan pada Tabel 2, merupakan sebuah element yang digunakan untuk proses pengambilan artikel. Penentuan element ini ditentukan berdasarkan sebuah element yang menjadi wadah untuk konten artikel yang dimiliki oleh website yang menjadi objek utama.

Tabel 1. Data Relasi

\begin{tabular}{|l|l|}
\hline \multicolumn{1}{|c|}{ Alamat Web } & \multicolumn{1}{c|}{ Kode Relasi } \\
\hline Kompas.com & $\underline{\text { xxxx.kompas.com }}$ \\
\hline Detik.com & m.detik.com/xxxx \\
\hline
\end{tabular}

Tabel 2. Data Element Konten Artikel

\begin{tabular}{|c|c|c|}
\hline No & Alamat Web & Element Konten Artikel \\
\hline 1. & KOMPAS.COM & div.kcm-read-text \\
\hline 2. & Detik.com & div.text_detail \\
\hline
\end{tabular}

\section{ANALISIS DAN PEMBAHASAN}

Proses indexing merupakan proses pengelompokkan data berdasarkan ketentuan relasi dan objek ontology. Pada proses indexing diterapkan metode ontology dengan ketentuan relasi 
berdasarkan kategori dari alamat web utama (main object). Tahap pengindeksan ontology ditampilkan pada Gambar 2.

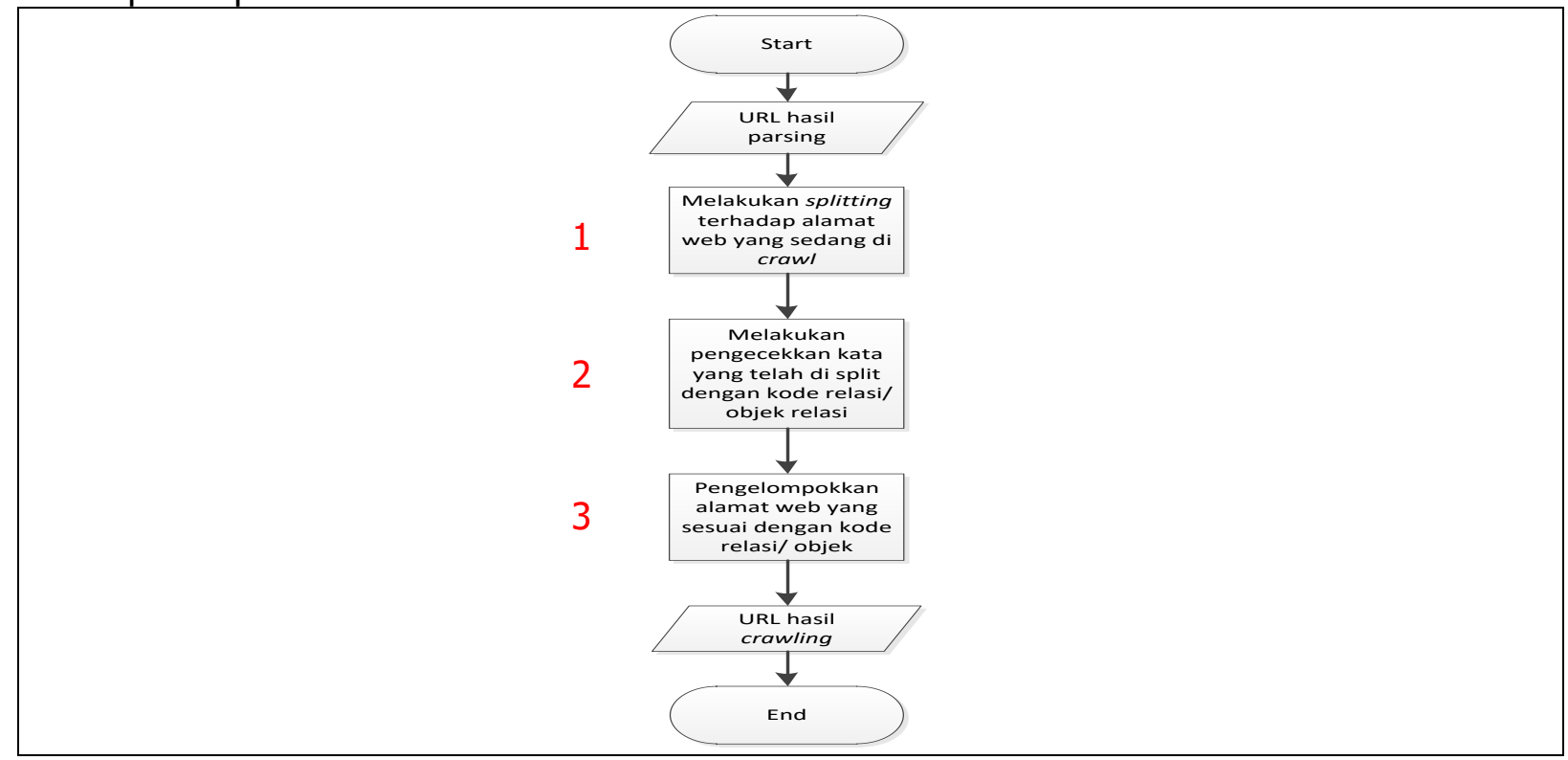

\section{Gambar 2. Flowchart Proses Indexing}

Pada proses indexing dilakukan 3 tahapan, yaitu :

1. Melakukan splitting pada alamat web yang sedang di crawl. Splitting yang dilakukan berdasarkan pemisahan tanda "/" dengan ketentuan relasi atau objek ontology.

Hasil parsing berupa sekumpulan alamat web pada objek "megapolitan" :

1. http://megapolitan.kompas.com/URL1

2. http://nasional.kompas.com/URL1

3. http://megapolitan.kompas.com/URL2

4. http://gramedia.com

5. http://megapolitan.kompas.com/URL3

6. http://nasional.kompas.com/URL2

Tahap splitting berdasarkan pemisahan "/" pada alamat web nomer 1 :

http://megapolitan.kompas.com/URL1

Hasil splitting alamat web nomer 1 :

megapolitan.kompas.com

2. Pengecekkan kata yang telah di split dengan relasi ontology atau objek ontology. Pada tahap ini, dilakukan pengecekkan kata dari tahap splitting dengan ketentuan ontology. Jika hasil craw/ sesuai dengan relasi atau objek ontology-nya, maka hasil craw/ diambil dan disimpan. Jika tidak maka hasil craw/ tidak diambil.

Tahap pengecekkan alamat web nomer 1 :

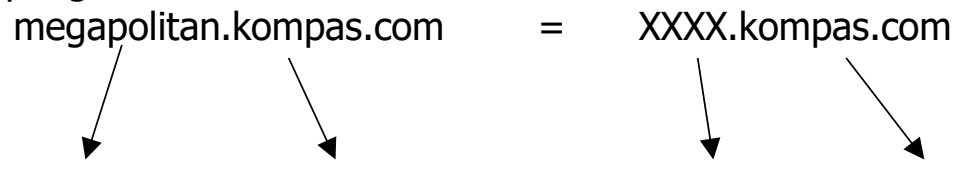

kategori alamat web kategori alamat web 
Tahap pengecekkan alamat web nomer 3 :

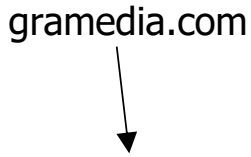

alamat web $\neq$

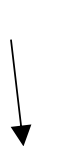

kategori
XXXX.kompas.com

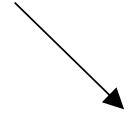

alamat web

Hasil pengecekkan :

1. http://megapolitan.kompas.com/URL1

2. http://nasional.kompas.com/URL1

3. http://megapolitan.kompas.com/URL2

4. http://megapolitan.kompas.com/URL3

5. http://nasional.kompas.com/URL2

3. Tahap terakhir, dilakukan pengelompokkan hasil crawl yang telah diambil berdasarkan dengan relasi ontology atau objek ontology.

Tahap pengelompokkan alamat web pada objek "megapolitan" :

1. http://megapolitan.kompas.com/URL1 http://nasional.kompas.com/URL1

2. http://megapolitan.kompas.com/URL2

3. http://megapolitan.kompas.com/URL3 http://nasional.kompas.com/URLz

Hasil indexing pada alamat web dengan objek "megapolitan" :

1. http://megapolitan.kompas.com/URL1

2. http://megapolitan.kompas.com/URL2

3. http://megapolitan.kompas.com/URL3

Hasil proses indexing dengan ontology adalah alamat web yang telah dikelompokkan berdasarkan ketentuan relasi ontology dan pengelompokkan berdasarkan objek ontology. Berbeda dengan proses indexing tanpa ontology yang hanya melakukan pengelompokkan berdasarkan urutan pengambilan alamat web, dimana hasil yang disimpan tidak jauh berbeda dengan hasil parsing. Sehingga hasil dengan ontology sudah terstruktur berdasarkan objeknya.

\subsection{Pengujian Kecocokkan Objek Ontology}

Pada pengujian kecocokkan objek ontology ini bertujuan untuk melihat kesesuaian objek pada pengambilan objek berdasarkan relasi ontology. Objek-objek tersebut diuji berdasarkan kecocokan bentuk kode dari url tersebut, dimana objek atau url memiliki bentuk yang sesuai dengan kode objek relasi dan kode alamat web pada relasi ontology.

Setelah keadaan atau kondisi sebuah objek atau url sesuai dengan relasi yang telah ditentukan, maka objek atau url tersebut merupakan bagian dari objek ontology. Sekumpulan objek yang memiliki keterkaitan dengan objek utamanya. Objek-objek berelasi ini yang kemudian diproses dan di-craw/ dalam tahap akhir crawling dengan ontology. Berikut analisis struktur ontology yang diuji untuk web kompas dan detik pada 21 Desember 2016, ditampilkan pada Tabel 3 dan Tabel 4. 
Tabel 3. Pengujian Struktur Ontology Kompas.com

\begin{tabular}{|c|l|l|l|l|}
\hline No & \multicolumn{1}{|c|}{ Url Relasi } & \multicolumn{1}{|c|}{$\begin{array}{c}\text { Objek Relasi } \\
(\mathbf{x x x x})\end{array}$} & $\begin{array}{c}\text { Alamat Web } \\
\text { (kompas) }\end{array}$ & $\begin{array}{c}\text { Validit } \\
\text { as }\end{array}$ \\
\hline 1. & http://nasional.kompas.com & Nasional & Kompas & Valid \\
\hline 2. & http://regional.kompas.com & Regional & Kompas & Valid \\
\hline 3. & http://megapolitan.kompas.com & Megapolitan & Kompas & Valid \\
\hline 4. & http://internasional.kompas.com & Internasional & Kompas & Valid \\
\hline 5. & http://olahraga.kompas.com & Olahraga & Kompas & Valid \\
\hline 6. & http://sains.kompas.com & Sains & Kompas & Valid \\
\hline 7. & http:///bisniskeuangan.kompas.com & Bisniskeuangan & Kompas & Valid \\
\hline 8. & http://bola.kompas.com & Bola & Kompas & Valid \\
\hline 9. & http://tekno.kompas.com & Tekno & Kompas & Valid \\
\hline 10. & http://vik.kompas.com/ & Vik & Kompas & Valid \\
\hline 11. & http://entertainment.kompas.com & Entertainment & Kompas & Valid \\
\hline 12. & http://otomotif.kompas.com & Otomotif & Kompas & Valid \\
\hline 13. & $\underline{\text { http://health.kompas.com }}$ & Health & Kompas & Valid \\
\hline 14. & http://female.kompas.com & Female & Kompas & Valid \\
\hline 15. & http://properti.kompas.com & Properti & Kompas & Valid \\
\hline 16. & http://travel.kompas.com & Travel & Kompas & Valid \\
\hline 18. & http://edukasi.kompas.com & Edukasi & Kompas & Valid \\
\hline 19. & http://kolom.kompas.com & Kolom & Kompas & Valid \\
\hline 20. & http://foto.kompas.com & Foto & Kompas & Valid \\
\hline 21. & http://video.kompas.com & Video & Kompas & Valid \\
\hline 22. & http://tv.kompas.com/ & TV & Kompas & Valid \\
\hline 23. & http://indeks.kompas.com/ & Indeks & Kompas & Valid \\
\hline 24. & http:///news.kompas.com/ & News & Kompas & Valid \\
\hline
\end{tabular}

Tabel 4. Pengujian Struktur Ontology Detik

\begin{tabular}{|c|l|l|l|l|}
\hline No & \multicolumn{1}{|c|}{ Url Relasi } & $\begin{array}{c}\text { Alamat Web } \\
(\mathbf{d e t i k})\end{array}$ & $\begin{array}{c}\text { Objek Relasi } \\
(\underline{\mathbf{x x x x}})\end{array}$ & Validitas \\
\hline 1. & http://m.detik.com/news & Detik & News & Valid \\
\hline 2. & http://m.detik.com//inance & Detik & Finance & Valid \\
\hline 3. & http://m.detik.com/hot & Detik & Hot & Valid \\
\hline 4. & http://m.detik.com/sport & Detik & Sport & Valid \\
\hline 5. & http://m.detik.com/sepakbola & Detik & Sepakbola & Valid \\
\hline 6. & http://m.detik.com/inet & Detik & Inet & Valid \\
\hline 7. & http://m.detik.com/oto & Detik & Oto & Valid \\
\hline 8. & http://m.detik.com/wolipop & Detik & Wolipop & Valid \\
\hline 9. & http://m.detik.com/health & Detik & Health & Valid \\
\hline 10. & http://m.detik.com/travel & Detik & Travel & Valid \\
\hline 11. & http://m.detik.com/food & Detik & Food & Valid \\
\hline 12. & http://m.detik.com/tv & Detik & Tv & Valid \\
\hline 13. & http://m.detik.com/foto & Detik & Foto & Valid \\
\hline 14. & http://m.detik.com/pasangmata & Detik & Pasangmata & Valid \\
\hline 15. & http://detik.com/pilkadadki & Detik & Pilkadadki & Valid \\
\hline & & & & \\
\hline
\end{tabular}

Setelah pengujian telah dilakukan, maka berdasarkan pencocokkan setiap objek tersebut didapatkan hasil $100 \%$ objek ontology sesuai dengan relasi ontology.

\subsection{Pengujian Respond Time Berdasarkan Kecepatan}

Pengujian respond time crawling dengan Ontology merupakan pengujian dari respond time sistem utama yang telah dirancang. Pengujian respond time crawling dengan Ontology tersebut dilakukanmenggunakan parameter kecepatan Dalam melakukan kedua pengujian 
tersebut dilakukan crawling dengan metode Ontology dan crawling tanpa menggunakan metode Ontology untuk medapatkan perbedaan hasil crawling menggunakan metode ontology dan tidak menggunakan metode ontology. Perbandingan respond time kecepatan crawling tersebut ditampilkan pada Tabel 5.

Tabel 5 Pengujian Respond Time Ontology

\begin{tabular}{|c|c|c|c|c|}
\hline Pengujian & $\begin{array}{c}\text { Crawl } \\
\text { Ontology } \\
\text { Kompas (s) }\end{array}$ & $\begin{array}{c}\text { Crawl } \\
\text { Kompas (s) }\end{array}$ & $\begin{array}{c}\text { Crawl } \\
\text { Ontology } \\
\text { Detik (s) }\end{array}$ & $\begin{array}{c}\text { Crawl Detik } \\
\text { (s) }\end{array}$ \\
\hline 1 & 5 & 7 & 3 & 4 \\
\hline 2 & 5 & 7 & 4 & 4 \\
\hline 3 & 7 & 9 & 7 & 11 \\
\hline 4 & 8 & 11 & 9 & 9 \\
\hline 5 & 4 & 4 & 4 & 4 \\
\hline 6 & 4 & 4 & 4 & 4 \\
\hline 7 & 9 & 7 & 4 & 7 \\
\hline 8 & 5 & 4 & 8 & 7 \\
\hline 9 & 4 & 5 & 12 & 7 \\
\hline 10 & 5 & 7 & 6 & 7 \\
\hline 11 & 7 & 9 & 2 & 7 \\
\hline 12 & 5 & 5 & 9 & 7 \\
\hline 13 & 5 & 8 & 5 & 7 \\
\hline 14 & 9 & 6 & 5 & \\
\hline 15 & 4 & 5 & 6 & 7 \\
\hline
\end{tabular}

Lebih cepat

Lebih lambat.

Kerenatan sama

Berdasarkan data pengujian yang telah dilakukan pada Tabel 5, maka didapatkan hasil $56,67 \%$ web crawler dengan ontology lebih cepat dibandingkan dengan tanpa menggunakan metode, $23,33 \%$ memiliki kecepatan yang sama dan $20 \%$ lebih lambat dari tanpa menggunakan metode.

\section{KESIMPULAN}

Berdasarkan penelitian Implementasi Web Crawler dengan Ontology yang diterapkan dalam studi kasus aplikasi pengarsipan didapatkan hasil sebagai berikut.

1. Pada proses penentuan objek relasi yang menjadi struktur ontology telah berhasil diimplementasikan dalam web crawler dengan presentase $100 \%$ objek relasi ontology sesuai dengan relasinya.

Pengindeksan Web crawler dengan ontology lebih cepat 56,67\% dibandingkan pengindeksan tanpa ontology.

\section{DAFTAR RUJUKAN}

[1] Ahmat Josi, Leon Andretti Abdillah, Suryayusra.2014. Penerapan Teknik Web Scraping Pada Mesin Pencari Artikel Ilmiah.

[2] Budi Yuwono, Savio L. Y. Lam, Jerry H.Ying, Dik L. Lee, 1996, A World Wide Web Resource Discovery System, in Proceedings of ICDE. 
[3] Eri Zuliarso, Khabib Mustofa.2009. Crawling Web Berdasarkan Ontology.

[4] Subuki, Makyun. 2011. Semantik Pengantar Memahami Makna Bahasa. Jakarta : Transpustaka.

[5] Sukanta Sinha, Rana Dattagupta dan Debajyoti Mukhopadhyay.2003. Web-page Indexing based on the Prioritize Ontology Terms.

[6] Yusuf, Muhammad. "Apa itu Web Crawler". Muhammad Yusuf Gunadarma. 2012. Web. 23 Oktober 2016

[7] Zebua, Javier., 2010, Aplikasi Pencarian Buku Berbasis Web Semantik Untuk Perpustakaan SMK Yadika 7 Bogor , UniversitasGunadarma. 